\title{
Modal Analysis of Car Ceiling Based on NVH Characteristics
}

\author{
Lu Wei \\ College of Mechanical Engineering, Jiamusi University \\ Jiamusi, China, 154007 \\ e-mail: lujunqi2001@163.com
}

Yao Jia*

College of Mechanical Engineering, Jiamusi University

Jiamusi, China, 154007

e-mail: jiauiyuyao@163.com

\author{
Liu Xiangdong \\ College of Mechanical Engineering, Jiamusi University \\ Jiamusi, China, 154007 \\ e-mail: liuxiangdong1973@163.com
}

\author{
Han Ping \\ College of Mechanical Engineering, Jiamusi University \\ Jiamusi, China, 154007 \\ e-mail: hanping_jtys @163.com \\ Wu Wanjiang \\ College of Mechanical Engineering, Jiamusi University \\ Jiamusi, China, 154007 \\ e-mail:wwj710919@163.com \\ Miao Yongfeng \\ College of Mechanical Engineering, Jiamusi University \\ Jiamusi, China, 154007 \\ e-mail: yongfeng@163.com
}

\begin{abstract}
In order to research the basic vibration characteristics of automobile, thus enhance the NVH characteristics for the improvement the comfort of occupants. The finite element model of car ceiling has been established and the modal analysis technology has been used, the effect of structural parameters on the ceiling mode has also been studied. Through the computer simulation, two important conclusions can be obtained. First, the increases of ceiling thickness were helpful to reducing vibration and noise, especially reducing low frequency noise inside the car. Second, when substituting the ceiling materials from low carbon steel to aluminum alloy, each order modal frequency slightly increased, but the whole modal vibration mode had no obvious changes, but the structure quality was decreased to about $50 \%$ with the reduction of material density, so the appropriate use of aluminum alloy in car ceiling is advantageous to the auto lightweight design, and the detail research should be carried based on the results.
\end{abstract}

Keywords- Noise/Vibration/Harshness $(\mathrm{NVH})$ characteristics; car ceiling, the finite element model; the modal analysis; lightweight

\section{INTRODUCTION}

With the continuous improvement of users' requirements for interior acoustic comfort, NVH characteristics of automobile was gradually evolved into the important performance design indexes of vehicle [1]. The panels of car body were the important components, the vibration produced will radiate noises to the surroundings when they suffered the outside incentives. Most of the car interior acoustic energy was radiated by the body panel components, so the research and the control of the sound radiation of the body panel components were especially important [2].

When the car body was under the broadband vibration incentives, many resonance peaks appeared within the scopes of the whole incentive frequencies, and then radiated noises into the surroundings. Because the area was large, the corresponding stiffness was weak, car ceiling was one of the quite important vibration sound components [3], the low-order modals of the whole body mostly carrying the local modal of ceiling which can lead to the resonance phenomenon, so controlling it will effectively inhibit the interior noise level [4-6].The modal analysis and study can effectively improve the acoustic characteristics of the whole body, taking the ceiling model of a car as example, the structure finite element model of car ceiling has been established, the thorough study of the inherent characteristics and the structure parameters has also been carried in the following parts, both thickness of ceiling and raw materials be used have been discussed based on the mode analysis.

\section{THE ESTABLISHMENT OF CEILING STRUCTURE USING FINITE ELEMENT MODEL}

The structure modal parameters of car ceiling can reflect the inherent vibration characteristics of the ceiling structure, the analysis of the ceiling structure modal was helpful to better grasp the mechanism of vibration and noise, thus provide the basis for the inner noise prediction and noise source diagnosis $[7,8]$.

Firstly, establishing a finite element model of the car ceiling structure in CATIA software, as shown in Fig .1, which according to the actual size of the actual car. Then importing the model to the ANSYS Solidwork software, through the performance definition of the material constants, the meshing results are shown as in Fig 2 . 


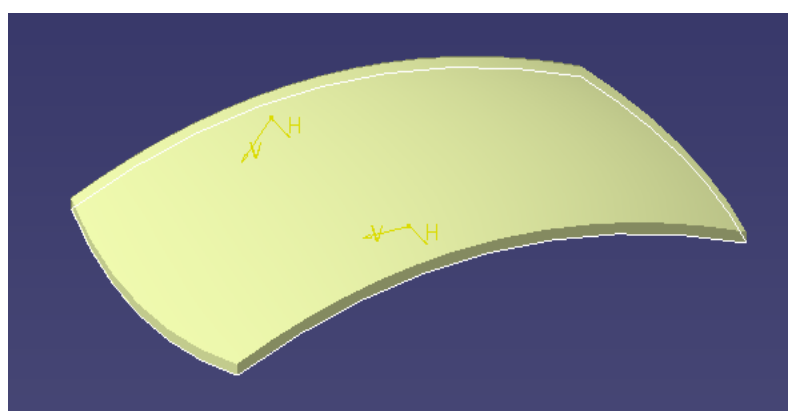

Figure 1. Three-dimensional structure of body ceiling using CATIA

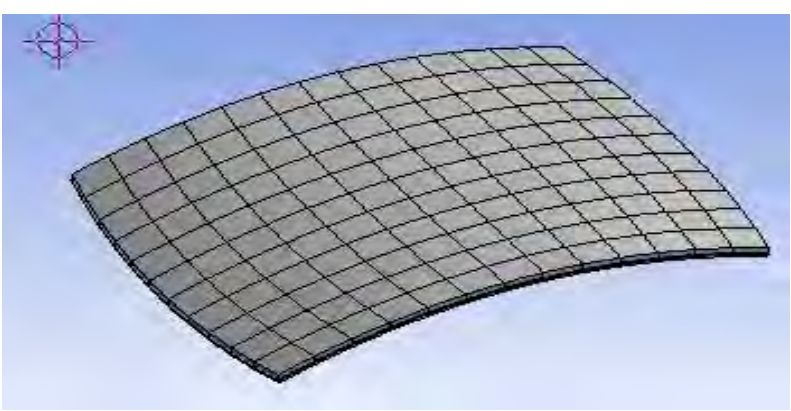

Figure 2. Meshing of finite element model

For the control of vehicle interior noise, low frequency below $200 \mathrm{~Hz}$ was a special frequency bands worthy of our attention because the low-frequency noise of the frequency bands can cause strong discomfort of drivers and passengers[9-11].The band was as part of low-order modal of ceiling structure. Therefore, by using the finite element modal analysis, the structure modal calculation has been done under the supposing that the quadrilateral displacement boundary condition was zero, the first sixorder frequency and inherent vibration mode of the whole structure will be obtained.

The thickness and raw material adopting of ceiling metal plate will have effect on the structure modal, but the extent of these structural parameters can influence the modal have yet to be proven. To fundamentally improve the modal characteristics, thus improve the NVH characteristics, the changing principles of modal frequency and vibration mode according to the changes of structure parameters must be researched.

\section{EFFECT OF PLATE THICKNESS ON BODY CEILING MODAL}

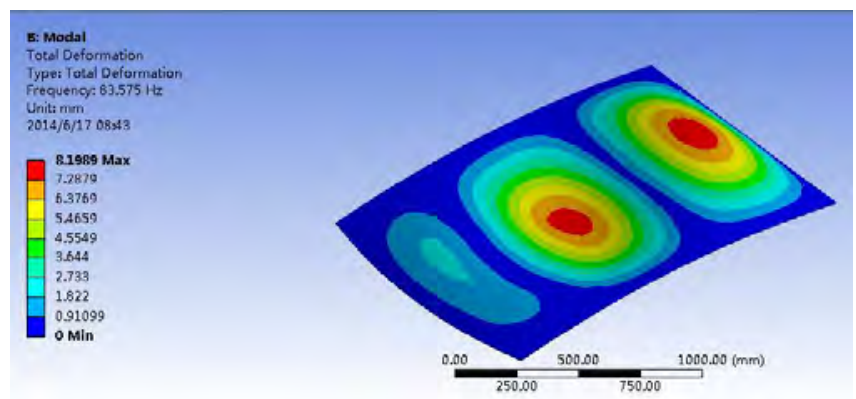

(a) The first order inherent vibration mode

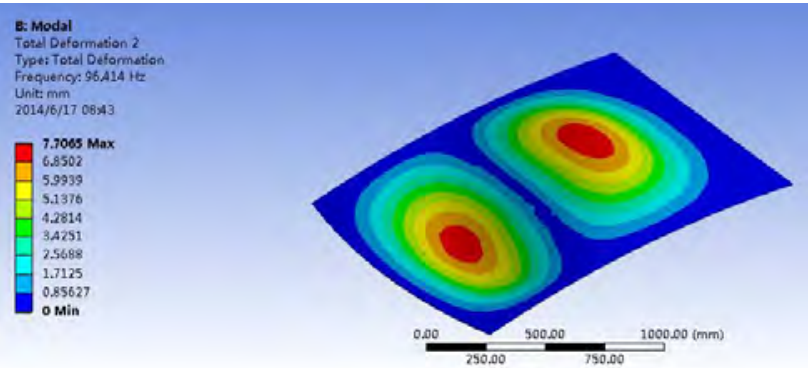

(b) The second order natural vibration mode

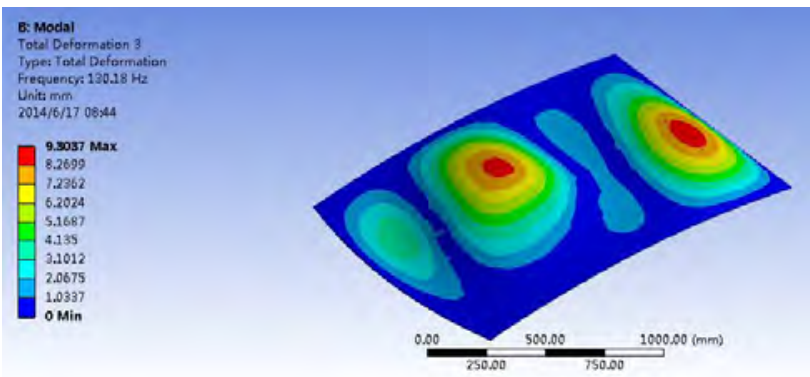

(c) The third order inherent vibration mode

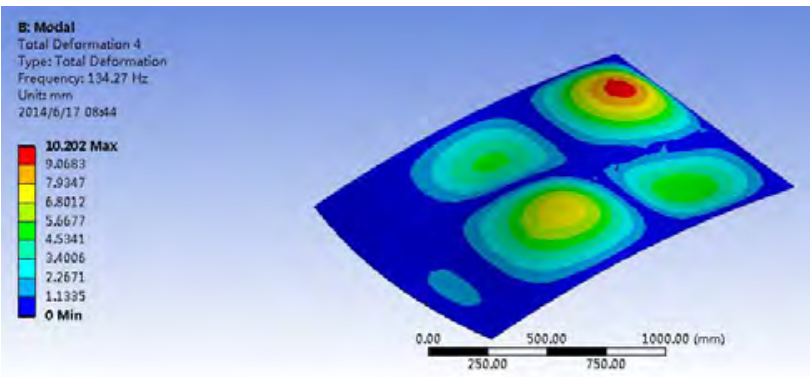

(d) The forth order inherent vibration mode

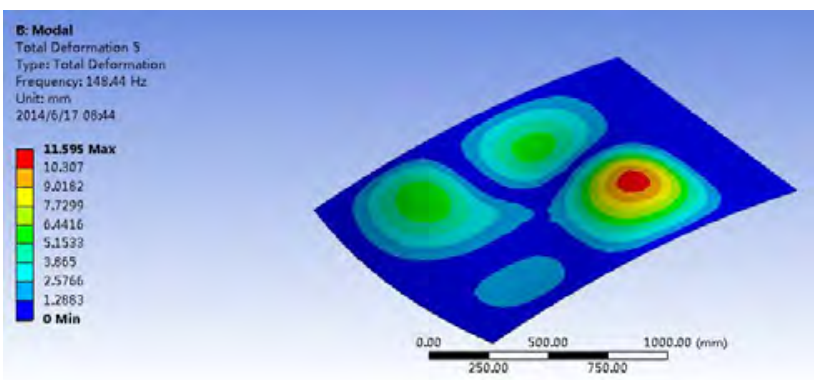

(e) The fifth order inherent vibration mode

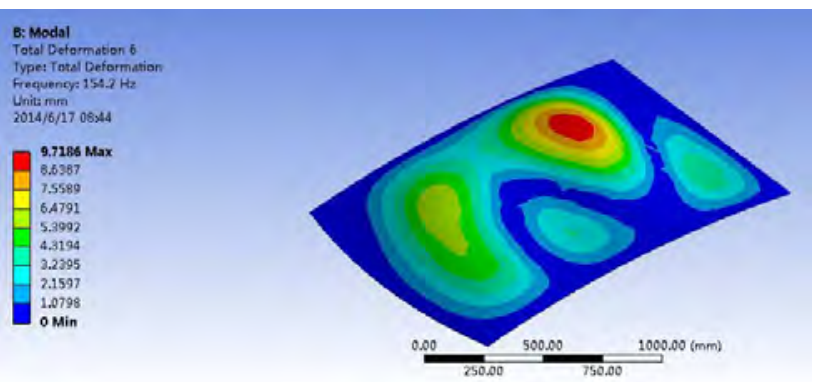

(f) The sixth order inherent vibration mode

Figure 3. First six order inherent vibration mode of $0.9 \mathrm{~mm}$ thickness low carbon steel ceiling 
For controlling the acoustic radiation of panel structure, one of the commonly used method was the change of the structure thickness. Low carbon steel as the most common material was chosen firstly, the commonly used three kinds of thickness $0.7 \mathrm{~mm}, 0.9 \mathrm{~mm}$, and $1.2 \mathrm{~mm}$, so the following analysis were the finite element mode of these three kinds of plate thickness. The performance parameters were: elastic modulus $\mathrm{E}=2 \times 10^{1 \mathrm{P}} \mathrm{Pa}$, poisson's ratio $\mu=$ 0.3 , density $\rho=7.8 \times 10^{3} \mathrm{~kg} / \mathrm{m}^{3}$. The first six order inherent vibration mode were shown in Fig .3 below adopting the thickness was $0.9 \mathrm{~mm}$ and the calculation results of the first six order modal frequencies of all the three thickness were shown in Table 1.

The first six order inherent vibration mode which was the main reasons reflect the deformation trend of the ceiling structure under the certain natural resonance frequency can be observed clearly in Fig .3.

Under each inherent frequency, the vibration deformations were different from each other, the first three modes were under the bending loads, the last three modes were under the torsion loading, the position and values of the largest deformation in each mode were also different. But the main deformation areas in the simulation figures were concentrated in the middle areas of the whole ceiling. To strengthen the rigid of the ceiling structure, we can start to study how to strengthen the weak parts of the middle parts of the ceiling both under the bending and twist loads obtained in the future work.

TABLE I. THE FIRST SIX ORDER MODAL FREQUENCIES OF DIFFERENT THICKNESS WITH LOW CARBON STEEL MATERIAL

\begin{tabular}{cccc}
\hline \multirow{2}{*}{ Mode } & \multicolumn{3}{c}{ Frequency(Hz) } \\
\cline { 2 - 4 } & $0.7 \mathrm{~mm}$ & $0.9 \mathrm{~mm}$ & $1.2 \mathrm{~mm}$ \\
\hline 1 & 81.322 & 83.575 & 84.924 \\
2 & 95.119 & 96.414 & 97.253 \\
3 & 126.68 & 130.18 & 132.07 \\
4 & 131.28 & 134.27 & 136.26 \\
5 & 145.75 & 148.44 & 150.09 \\
6 & 152.13 & 154.2 & 155.5 \\
\hline
\end{tabular}

From Table 1, the each order modal frequencies increased with the increase of thickness were listed, the frequency values were increased with the thickness of ceiling. The increase of thickness was helpful to reduce vibration and noise, and improved the low frequency noise inside the car. But obviously the increase of thickness can make the structure weight also increased largely, especially, the frequency change only under the increase of thickness was not obvious. Also it was disadvantageous for structural lightweight design, so the thickness increases were not a suitable optimization way to the ceiling design for the NVH characteristics improvement.

\section{EFFECT OF LIGHTWEIGHT MATERIAL ON BODY CEILING MODAL}

In order to examine the influence of different metal plate materials on the finite element modal of body ceilings, the above finite element model of car ceiling was used, but the ceiling materials was defined as lightweight aluminum alloy materials. The same boundary conditions were adopted, in this condition, elastic modulus $\mathrm{E}=7 \times$
$10^{10} \mathrm{~Pa}$, poisson's ratio $\mathrm{u}=0.33$, density $\rho=2.7 \times 10^{3}$ $\mathrm{kg} / \mathrm{m}^{3}$. the first six order modals of $0.9 \mathrm{~mm}$ thickness of body ceiling structure have been calculated, and the first six order inherent vibration mode were shown in Fig .4.

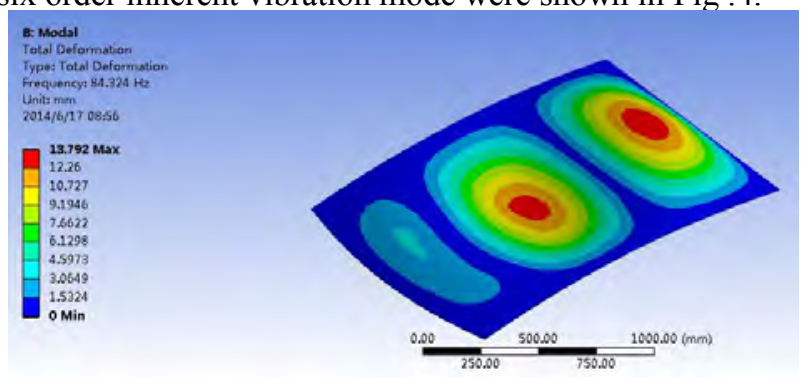

(a) The first order inherent vibration mode

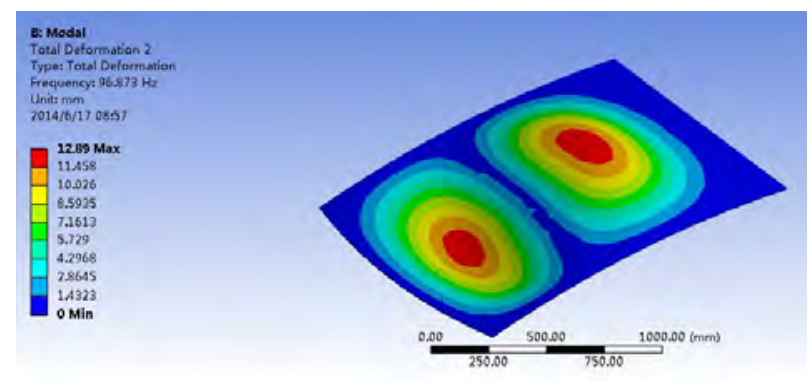

(b) The second order natural vibration mode

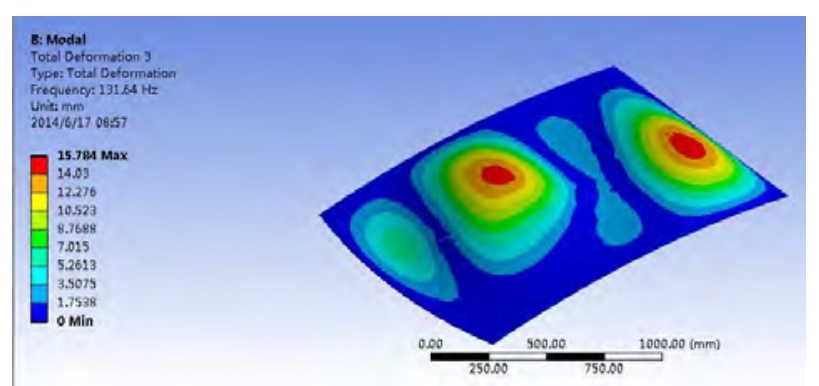

(c) The third order inherent vibration mode

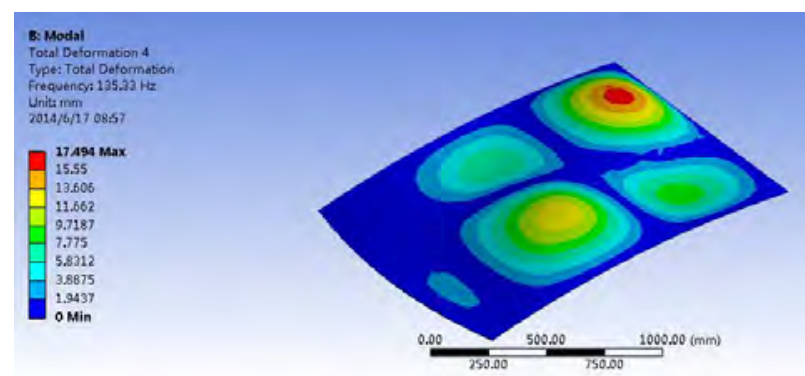

(d) The forth order inherent vibration mode

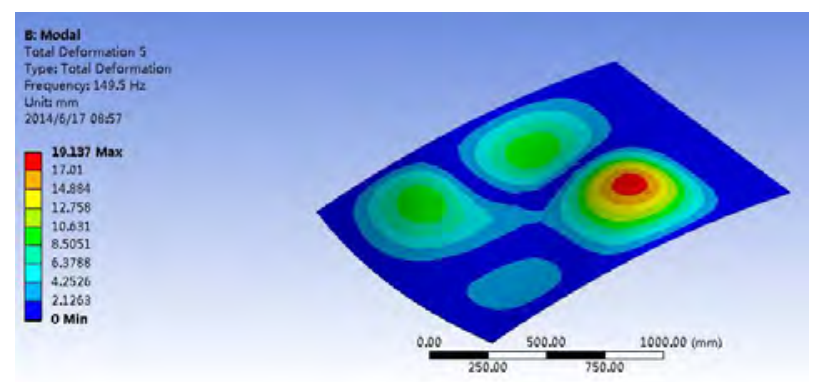

(e) The fifth order inherent vibration mode 


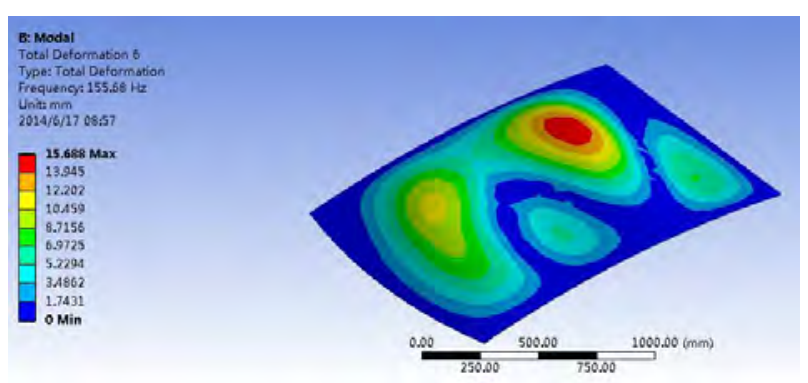

(f) The sixth order inherent vibration mode

Figure 4. First six order inherent vibration mode of $0.9 \mathrm{~mm}$ thickness aluminium alloy ceiling

To meet the requirement of stiffness, the thickness of the aluminium alloy plate commonly used in engineering must be not less than $1.2 \mathrm{~mm}$. So calculating the modal frequency of the ceiling with thickness of $0.9 \mathrm{~mm}$ and 1.2 $\mathrm{mm}$ for the comparison purpose, the results and the comparison data of $0.9 \mathrm{~mm}$ thickness low carbon steel materials and aluminium alloy with $0.9 \mathrm{~mm}$ and $1.2 \mathrm{~mm}$ thickness were shown in table 2.

TABLE II. THE FIRST SIX ORDER MODAL FREQUENCY OF DIFFERENT MATERIALS BODY CEILING

\begin{tabular}{cccc}
\hline \multirow{2}{*}{ Mode } & \multicolumn{3}{c}{ Frequency(Hz) } \\
\cline { 2 - 4 } & $\begin{array}{c}\text { 0.9mm low } \\
\text { carbon steel }\end{array}$ & $\begin{array}{c}\text { 0.9mm aluminium } \\
\text { alloy }\end{array}$ & $\begin{array}{c}1.2 m m \text { aluminium } \\
\text { alloy }\end{array}$ \\
\hline 1 & 83.575 & 84.324 & 86.122 \\
2 & 96.414 & 96.873 & 98.064 \\
3 & 130.18 & 131.64 & 134.13 \\
4 & 134.27 & 135.33 & 137.96 \\
5 & 148.44 & 149.5 & 151.65 \\
6 & 154.2 & 155.68 & 157.51 \\
\hline
\end{tabular}

The vibration deformations were different from each other in Fig .4, the first three modes were under the bending loads, the last three modes were under the torsion loading, the position and values of the largest deformation in each mode were also different. By the comparison of Fig .4 and Fig .2, the main deformation areas in the simulation figures were concentrated in the middle areas of the whole ceiling under the first six order inherent frequency. As in table 2, when the thickness of metal plate were the same, substituting low carbon steel by aluminum alloy, each order modal frequency of the structure had a slight rise, each order modal vibration has small influence on the occupants. The first six order modal frequency got by $12 \mathrm{~mm}$ thickness low carbon steel and aluminium alloy were basically the same in Table 1 and Table 2. So substituting low carbon steel for aluminium alloy had almost no effect on the vibration and NVH characteristics. But the structure quality was decreases to about $50 \%$ with the reduction of material density. In order to ensure the structure stiffness, the recommend thickness of aluminum alloy ceiling was $1.2 \mathrm{~mm}$ for enough stiffeness and was highly beneficial for the automotive lightweight design.

\section{CONCLUSIONS}

(1) From the modal analysis results of the ceiling structure under ANSYS solidwork software, the deformation results under different inherent frequency can be obtained, the first six-order inherent frequency will also be simulated. So it was useful to predict the weak parts of ceiling structure, thus the improvement methods can be put forward.

(2) The local vibration of ceiling structure appeared under different ceiling thickness and materials can be got, thus the change principles of the car interior noise level can be deduced. Through the modal analysis, the mechanism of vibration and noise can be better grasped, and then provide the basis for indoor NVH characteristics prediction.

(3) The thickness increase will help to reduce vibration and noise. When the ceiling material was adopted aluminium alloy, the modal frequencies were slightly higher than low carbon steel. Modal vibration mode had no obvious change for the occupants. But the quality of the ceiling structure was decreases to half with the reduction of material. Aluminium alloy was the appropriate alternatives for the ceiling to realize the auto lightweight design.

\section{ACKNOWLEDGMENT}

This project was funded by the Heilongjiang Educational Office Scientific Research Program (12541794).

\section{REFERENCES}

[1] Wang Haohan, Ding Weiping, Wang Yanke, He Sendong, Yang Mingliang, Li Bo. Typical Technologies of Automobile Noise Control and Their System ic Application in Design Process[J]. Noise \& vibration control, 2008, 2 (1): 56-59

[2] He Yusheng. Automotive noise control, Beijing: Mechanical industry press[M],1999

[3] Gu Zhengqi. Car body, Beijing: People's traffic press[M], 2008

[4] Ding Weiping. Study on the low noise optimization design for an automobile body structure[J]. Mechanical design \& manufacturing, 2001, 28(1): 50-52

[5] Bai Shengyong, JIN Xiaoxiong, DINGYulan, ZHOU Hong Acoustic Modal Analysis of Automobile Passenger Compartments[J], Jouranl of Tongji University, 2000, 28(2): 206210

[6] Ma Liming, Zhu Zhimin, An Zhanfei, Li Weiguang, Yao Bin. Modal analysis of a car BIW[J], Jouranl of Vibration and Shock, 2013, 32 (21): 214-218

[7] Zhang Lijun, Jin Xiaoxiong, Yu Zhuoping and Zhou Hong. The car interior noise control method[J], Automotive Engineering, 2002,25(1): 38-40

[8] Deng Limei, Deng Yadong, Song Jingliang. Body finite element modal analysis of influence factors of research[J], Beijing Automotive Engineering, 2007, (27)4: 28-30

[9] Amiya. R. Mohanty. Structure-borne noise reduction in a truck cab interior using numerical techniques[J]. Applied Acoustics, 2000, 59(8): 78-84

[10] Kim. S. H.. Structural-acoustic modal coupling analysis and application to noise reduction in vehicle passenger compartment [J]. Journal of Sound and Vibration. 1999, 225(5):125-129

[11] Ding Tao, Yu Shaochun. Frame construction mode numerical simulation analysis based on ANSYS[J]. Journal of Liaoning Technical University(Natural Science), 2010, 29(5): 43-44 